\title{
Revisiting Planting Date and Cultivar Effects on Soybean Sudden Death Syndrome Development and Yield Loss
}

David A. Marburger, Department of Agronomy, University of Wisconsin-Madison, 1575 Linden Drive, Madison, WI 53706; Damon L. Smith, Department of Plant Pathology, University of Wisconsin-Madison, 1630 Linden Drive, Madison, WI 53706; and Shawn P. Conley, Department of Agronomy, University of Wisconsin-Madison

\begin{abstract}
Marburger, D. A., Smith, D. L., and Conley, S. P. 2016. Revisiting planting date and cultivar effects on soybean sudden death syndrome development and yield loss. Plant Dis. 100:2152-2157.

The impact of today's optimal planting dates on sudden death syndrome (SDS) (caused by Fusarium virguliforme) development and soybean yield loss are not yet well understood. Field trials established in Hancock, Wisconsin during 2013 and 2014 investigated interactions between planting date and cultivar on SDS development and soybean yield. In 2013, disease index (DX) levels differed among cultivars, but results showed no difference between the 6 May and 24 May planting dates. Significantly lower DX levels were observed for the 17 June date. Greatest yields were found in the 6 May planting date, and yield losses were 720

(17\%), 770 (20\%), and $400 \mathrm{~kg} \mathrm{ha}^{-1}(12 \%)$ for the 6 May, 24 May, 17 and June planting dates, respectively. In 2014, cultivars again differed for DX, but results showed highest DX levels in the 5 May planting date, with little disease observed in the 22 May and 11 June dates. Yield losses were $400(12 \%)$ and $270 \mathrm{~kg} \mathrm{ha}^{-1}(9 \%)$ for the 5 May and 22 May dates, respectively, but no difference was found in the 11 June date. Despite the most symptom development, these results suggest early May planting coupled with appropriate cultivar selection provides maximum yield potential and profitability in Wisconsin.
\end{abstract}

Sudden death syndrome (SDS) is a disease on soybean (Glycine $\max$ [L.] Merr.) caused by the soil-borne fungus Fusarium virguliforme O'Donnell \& T. Aoki (synonym: F. solani [Mart.] Sacc. f. sp. glycines) (Aoki et al. 2003). SDS was first observed in Arkansas in 1971 and has become widespread throughout the north-central United States since then (Hartman et al. 2015). Although SDS is a relatively new disease in Wisconsin (Bernstein et al. 2007), further work has shown $F$. virguliforme has spread to the majority of soybean-producing areas in the state (Marburger et al. 2014).

SDS ranked among the top 10 yield-suppressing diseases in the United States in 11 of 12 years from 1996 to 2007, and it often ranked second to fifth in those years (Wrather and Koenning 2009). Further work by Koenning and Wrather (2010) showed yield loss attributed to SDS totaled 1.5 million metric tons from 2008 to 2009, making it the fifth most yield-suppressing soybean disease across those two years. Soybean yield loss due to SDS is dependent on cultivar susceptibility, rainfall and temperature, soybean growth stage when symptoms appear, and symptom severity (Leandro et al. 2012). Foliar symptom expression is the result of phytotoxins secreted by the fungus and translocated through the xylem from the roots to the leaves (Brar et al. 2011). Symptoms typically begin during reproductive growth on upper leaves, with the appearance of chlorotic mottling and interveinal necrosis (Roy et al. 1997), and advanced symptoms result in leaf curling and premature defoliation (Leandro et al. 2012). Yield loss is the result of reduced photosynthetic area, premature defoliation, flower and pod abortion, and reduced seed size (Roy et al. 1997). With severe infection, symptoms appearing in the early reproductive growth stages typically reduce seed number by inducing flowering and pod abortion. Symptoms appearing during the pod-filling stages typically reduce yield through decreased seed size (Luo et al. 2000). Yield loss up to $80 \%$ in individual fields has been attributed to SDS, but yield loss of 5 to $15 \%$ is more common (Roy et al. 1997).

Corresponding author: D. A. Marburger; E-mail: dmarburger@wisc.edu

Accepted for publication 18 May 2016.

http://dx.doi.org/10.1094/PDIS-12-15-1411-RE

(C) 2016 The American Phytopathological Society
Currently, cultivar selection is considered the best management practice for controlling SDS (Leandro et al. 2012; Roy et al. 1997) Research has demonstrated there are significant differences in cultivar response to SDS development (Hershman et al. 1990; Hirrel 1986; Rupe et al. 1991; Vick et al. 2006; Wrather et al. 1995), and extensive research has been performed to identify sources of resistance (Hartman et al. 1997; Hnetkovsky et al. 1996; Mueller et al. 2002, 2003) as well as understanding the underlying mechanism for root infection resistance and reduction in toxin development and translocation (Leandro et al. 2012). No current commercial cultivars have complete resistance to SDS, but moderately resistant genotypes have been identified and made available to producers (Brzostowski et al. 2014).

Using agronomic practices, such as crop rotation and tillage, to manage SDS have provided inconsistent results (Abdelsamad et al. 2012; Hirrel 1987; Rupe et al. 1997; Vick et al. 2003; Von Qualen et al. 1989; Wrather et al. 1995; Xing and Westphal 2009; Yang and Navi 2010). Unlike crop rotation and tillage, using planting date as an agronomic practice for control of SDS has provided more consistent results, with evidence that delaying planting date leads to reduced SDS foliar symptom development. A three-year study in Kentucky examining planting date and cultivar influence on SDS development showed that mid-May planting dates resulted in higher SDS levels compared with mid-June through early-July in 1987 and 1988 (Hershman et al. 1990). However, the reverse occurred for several cultivars in 1986, but some cultivars in that same year did not differ in amount of symptom development across the midMay to late-June planting dates. A four-year study in Missouri also showed that mid-May planting dates exhibited higher SDS foliar symptoms compared with mid- and late-June planting dates in three of the four years that had foliar symptom development (Wrather et al. 1995). The explanation for increased symptom development in earlyversus late-planted soybean is often attributed to soil conditions. Infection by $F$. virguliforme favors cool soil temperatures and high soil moisture, conditions that are typically associated with early-planted soybean (Scherm and Yang 1996).

While delaying planting date appears to be a reliable management practice for controlling SDS symptom development, the early planting dates used by Hershman et al. (1990) and Wrather et al. (1995) are no longer consistent with optimal planting dates used in soybean production today. It is evident that planting dates in the Midwest have 
trended toward earlier calendar dates in the past 30 years (Rowntree et al. 2013), and research has shown optimum planting dates for maximizing yield potential range from late-April to mid-May for most Midwestern states (De Bruin and Pedersen 2008; Gaspar and Conley 2015; Heatherly and Elmore 2004). However, the impact of currently recommended planting dates on SDS foliar symptom development and soybean yield loss have not yet been examined. Therefore, the objective of this study was to quantify planting date and cultivar effects on SDS foliar symptom development and soybean yield loss.

\section{Materials and Methods}

Inoculum preparation. Single-spore cultures from three Fusarium virguliforme isolates (00-11-183, NRRL22823, and INS12-10 \#3-1) were grown on potato dextrose agar (PDA, dehydrated) (Fisher Scientific, Pittsburg, PA) for 14 days at $23 \pm 2{ }^{\circ} \mathrm{C}$ with 12 -h diurnal light. These isolates originated in Indiana and were used because pure isolates of $F$. virguliforme from Wisconsin were not available at the time of inoculation preparation in 2013 (APHIS permit P526P-14-02376). In 2014, the INS12-10 \#3-1 isolate was substituted with an isolate (Soy-1) collected from Wisconsin during the 2013 growing season. Oat (Avena sativa L.) seed was used as the carrier, and a batch of oat seed containing the needed amount for each planting date was prepared 30 days prior to each of the three target planting dates. The seed was soaked overnight using distilled water in a 1:1 ratio. Excess water was drained, and the grain was autoclaved on two consecutive days, for $60 \mathrm{~min}$ at $121^{\circ} \mathrm{C}$. The sterilized oat grain was infested, adding $25,1-\mathrm{cm}^{2}$ sections of colonized PDA cut from a standard petri plate to $2.3 \mathrm{~kg}$ of oat grain. Infestation of the oat grain was completed individually for each isolate, with subsequent incubation at $22^{\circ} \mathrm{C}$ for 28 days. Two days prior to intended use, infested grain was dried at $30^{\circ} \mathrm{C}$. Immediately prior to planting, infested oat grain from all three isolates was mixed.

Experimental design. A field experiment was conducted at the Hancock Agricultural Research Station ( $\left.44^{\circ} 18^{\prime} \mathrm{N}, 89^{\circ} 33^{\prime} \mathrm{W}\right)$ near Hancock, Wisconsin, during the 2013 and 2014 growing seasons. The experimental design was a randomized complete block in a split-split plot arrangement, with four replications. Main plots consisted of three target planting dates. Planting occurred on 6 May, 24 May, and 17 June in 2013 and on 5 May, 22 May, and 11 June in 2014. Subplots consisted of 10 cultivars ranging in SDS foliar symptom reaction, according to the respective companies (Table 1). Sub-subplots (i.e., the experimental unit) consisted of two inoculation treatments (noninoculated and inoculated). Sub-subplots were two rows $6.4 \mathrm{~m}$ long spaced $76 \mathrm{~cm}$ apart and were seeded at 346,000 seeds $\mathrm{ha}^{-1}$. A custom-built plot planter with John Deere (Deere and Co., Moline, IL) row units was used for planting. Inoculation was performed using a Gandy multipurpose hopper (Gandy Company, Owatonna, MN) attached to the planter, which metered the $F$. virguliforme infested oat seed to the top of the seed tube in the row unit at a rate of $3.3 \mathrm{~g} \mathrm{~m}^{-1}$ of linear sub-subplot row. This allowed the infested oat seed to be placed in-furrow next to the soybean seed at the time of planting. The previous crop for both years was corn. Conventional tillage was used and was accomplished by a chisel plow in the fall and two passes of field cultivation in the spring, before planting. Soil samples were collected from each sub-subplot for soybean cyst nematode (SCN) (Heterodera glycines Ichinoche) analysis. Samples were collected in the spring immediately after sowing (i.e., prior to emergence) and in the fall at R8 (Fehr et al. 1971). A soil sample consisted of 10 soil cores to a depth of $20 \mathrm{~cm}$ with a diameter of $1.9 \mathrm{~cm}$, arbitrarily taken throughout the sub-subplot. Soil samples were submitted to the Plant Nematology Laboratory at the University of Missouri for analysis (eggs $100 \mathrm{~cm}^{3}$ ). Fertilizers and pesticides were applied according to University of Wisconsin-Madison best management recommendations. Because the soil type at this location was a Plainfield sand (sand, mixed, mesic Typic Udipsamments), the entire experiment was irrigated as needed, using a lateral overhead irrigation system (Valley Irrigation, Valley, NE). The total amount of irrigation applied each month is listed in Table 2.

Foliar SDS symptom ratings were recorded weekly, beginning with the first visual symptoms at the R5 growth stage (Fehr et al.
1971) and continued up to the R7 growth stage. Ratings were conducted using previously reported methods (Njiti et al. 1998). Disease incidence (DI) was estimated as the percentage of symptomatic plants within a plot. Disease severity (DS) was determined using a 1 to 9 scale: $1=1$ to $10 \%$ of leaf surface chlorotic or 1 to $5 \%$ necrotic; $2=10$ to $20 \%$ of leaf surface chlorotic or 6 to $10 \%$ necrotic; $3=20$ to $40 \%$ of leaf surface chlorotic or 11 to $20 \%$ necrotic; $4=40$ to $60 \%$ of leaf surface chlorotic or 21 to $40 \%$ necrotic; $5=$ greater than $60 \%$ of leaf surface chlorotic or greater than $40 \%$ necrotic; $6=$ premature leaf drop up to $33 \%$ defoliation; $7=$ premature leaf drop up to $66 \%$ defoliation; $8=$ premature leaf drop greater than two-thirds defoliation; and $9=$ premature death. Using the DI and DS scores, a DX measure was also calculated using the formula DX $=\mathrm{DI} \times \mathrm{DS} \div 9$ (Njiti et al. 1998). The final rating for the first, second, and third planting dates occurred on September 4, 9, and 23 in 2013 and on August 25 and September 2 and 16 in 2014.

At plant maturity, soybean seed was mechanically harvested, using an Almaco plot combine (Almaco, Nevada, IA). Seed weight and moisture were collected from the two rows of each sub-subplot, and seed moisture was adjusted to $13 \%$ moisture content. Harvest occurred on October 8 and 22 in 2013 and on October 9, 10, and 22 in 2014.

Statistical analysis. Correlation analyses were conducted for yield, DX, and spring and fall SCN populations. Correlations were performed by planting date within each year, by combining the data from both inoculation treatments for each planting date. All correlation coefficients were calculated based on the Pearson productmoment correlation using PROC CORR in SAS version 9.3 (SAS Institute, Cary, NC). Mixed-model analysis of variance (ANOVA) was also conducted using PROC GLIMMIX within SAS. Initial analysis for DX and yield revealed a highly significant difference $(P<$ $0.0001)$ between years for each variable. Therefore, all models were constructed and analyzed individually for each year. For the yield analysis, planting date, cultivar, inoculation, all two- and three-way interactions were considered fixed effects. Replication, replication $\times$ planting date, replication $\times$ planting date $\times$ cultivar, and the overall error term were considered random effects. For the DX analysis, the final rating for each planting date was used, and the values were transformed using the equation $\log _{10}$ ('rating' +1 ). Because $<1 \%$ of the noninoculated sub-subplots expressed foliar SDS symptoms, the noninoculated treatment was removed from the analysis. Therefore, planting date, cultivar, and their interaction were considered fixed effects, and replication, replication $\times$ planting date, and the overall error term were considered random effects. For all analyses,

Table 1. Soybean cultivar information including brand, maturity group, and sudden death syndrome (SDS) ratings

\begin{tabular}{llccc}
\hline & & & \multicolumn{2}{c}{ SDS rating } \\
\cline { 3 - 5 } Brand $^{\mathbf{x}}$ & Cultivar & $\begin{array}{c}\text { Maturity } \\
\text { group }\end{array}$ & $\begin{array}{c}\text { Brand } \\
\text { ratingy }^{\mathbf{y}}\end{array}$ & $\begin{array}{c}\text { Current study } \\
\text { rating }^{\mathbf{z}}\end{array}$ \\
\hline Asgrow & AG1931 & 1.9 & 6 & $\mathrm{~A}$ \\
Channel & CH2105R2 & 2.1 & 2 & $\mathrm{~L}$ \\
Pioneer & P92Y11 & 2.1 & 4 & $\mathrm{H}$ \\
Pioneer & P92Y12 & 2.1 & 4 & $\mathrm{~A}$ \\
Channel & CH2305R2 & 2.3 & 5 & $\mathrm{H}$ \\
Pioneer & P92Y32 & 2.3 & 6 & $\mathrm{H}$ \\
Asgrow & AG2431 & 2.4 & 6 & $\mathrm{~A}$ \\
Asgrow & AG2531 & 2.5 & 4 & $\mathrm{~A}$ \\
Pioneer & P92Y51 & 2.5 & 7 & $\mathrm{~L}$ \\
Pioneer & P92Y53 & 2.5 & 6 & $\mathrm{~A}$ \\
\hline
\end{tabular}

x Asgrow and Channel (Monsanto Co., St. Louis); Pioneer (Pioneer Hi-Bred International, Inc., Johnston, IA).

y Reported SDS rating by the brand. Asgrow and Channel cultivars on a 1 to 9 scale with $1=$ most resistant. Pioneer cultivars on a 1 to 9 scale with $1=$ most susceptible.

${ }^{\mathrm{z}}$ Current study rating was determined based on the amount of foliar SDS symptom development observed in this study in both 2013 and 2014; $\mathrm{H}=$ highest level of foliar symptom development; $\mathrm{L}=$ lowest level of foliar symptom development; $\mathrm{A}=$ average foliar symptom development. 
fixed effects were tested for significance at $\alpha=0.05$, and means comparisons were calculated based on Fisher's protected least significant difference. The SLICE option in SAS was used to compare means of significant interactions. Degrees of freedom were calculated using the Kenward-Rogers method (Littell et al. 2006).

\section{Results}

Environment. The 2013 growing season had below normal temperatures in April, June, July, and August, with close to average temperatures in May and September (Table 2). Average temperatures across the entire growing season were $1.1^{\circ} \mathrm{C}$ below normal. Aboveaverage precipitation occurred in April, May, and June, but belowaverage rainfall occurred for the remainder of the growing season, resulting in a $45 \mathrm{~mm}$ deficit for the entire growing season.

In 2014, below-average temperatures were observed in April and May (Table 2). June temperatures were slightly above normal, and the remainder of the growing season had below-average temperatures, resulting in an average temperature $1.4^{\circ} \mathrm{C}$ below normal across the entire growing season. Above-average rainfall was observed in April, followed by below-average rainfall in May. This alternating pattern of above-average rainfall for one month followed by belowaverage rainfall for the next month was observed for the remainder of the growing season. Season-long accumulated precipitation was $60 \mathrm{~mm}$ above normal.

SDS ratings. No significant correlations $(P>0.05)$ were found between DX and spring SCN population and between DX and fall SCN population within any of the three planting dates in 2013 and 2014 (data not shown). The only significant correlation was between spring SCN population and fall SCN population for the 11 June planting date in $2014(r=0.4214, P=0.0001)$.

A planting date $\times$ cultivar interaction was observed for DX in 2013 (Table 3). Disease index values differed among cultivars within the 6 May and 24 May planting dates; however, DX values for each cultivar were similar between the 6 May and 24 May planting dates (Table 4). Because little foliar symptom development was observed in the 17 June planting date, no differences among cultivars were found, and all values were lower for each cultivar compared with the earlier planting dates. The two cultivars that had the best SDS ratings provided by their respective companies $(\mathrm{CH} 2105 \mathrm{R} 2$ and P92Y51) were the only two cultivars consistently exhibiting the lowest DX values within the first and second planting dates. Four cultivars (AG2531, CH2305R2, P92Y11, and P92Y32) were those that consistently showed the highest DX values within the first and second planting dates; however, only one of these cultivars (P92Y11) was consistent with having the most susceptible SDS rating provided by its respective company. For the remaining cultivars, results were inconsistent between company SDS rating and DX values observed in this study.

The planting date $\times$ cultivar interaction for DX was also significant in 2014 (Table 3). Largest DX values were observed in the 5 May planting date, with few foliar symptoms found in the 22 May and 11 June planting dates (Table 4). Cultivars differed in DX within the 5 May date, but no cultivar differences were found in the 22 May and 11 June planting dates. Within the 5 May planting date, the cultivars $\mathrm{CH} 2105 \mathrm{R} 2$ and $\mathrm{P} 92 \mathrm{Y} 51$ showed the lowest DX values. This was consistent with the DX results from the first and second planting dates in 2013. Furthermore, three of the four cultivars that exhibited the highest DX values in 2013 (CH2305R2, P92Y11, and P92Y32) also exhibited the highest DX values in 2014 (Table 4).

Yield. Negative correlations were found between yield and DX within the 6 May $(r=-0.5052, P<0.0001), 24$ May $(r=-0.5234$, $P<0.0001)$, and 17 June $(r=-0.3274, P=0.0030)$ planting dates in 2013. A negative correlation was identified between yield and spring SCN population but only within the 17 June planting date $(r=-0.3228, P=0.0035)$. Negative correlations were found between yield and fall SCN population within the first $(r=-0.3358, P=$ $0.0027)$, second $(r=-0.2397, P=0.0322)$, and third $(r=-0.4190$, $P=0.0001)$ planting dates in 2013. In the following year, yield and DX were again negatively correlated but only in the 5 May planting date $(r=-0.3171, P=0.0042)$. Unlike 2013, no significant correlations $(P>0.05)$ were found between yield and spring or fall SCN population for the three planting dates in 2014 (data not shown).

For the ANOVA results, planting date, cultivar, inoculation, and the planting date $\times$ inoculation interaction were significant in 2013 (Table 3). For the planting date $\times$ inoculation interaction, the yield difference between noninoculated and inoculated plots in the 6 May planting date was $720 \mathrm{~kg} \mathrm{ha}^{-1}(17 \%)$ (Fig. 1A). A larger yield difference, $770 \mathrm{~kg} \mathrm{ha}^{-1}(20 \%)$, was observed in the 24 May planting date; however, average yield for the 6 May planting date was 350 $\mathrm{kg} \mathrm{ha}^{-1}(8 \%)$ greater than the 24 May planting date. For the 17 June date, inoculated plots yielded $400 \mathrm{~kg} \mathrm{ha}^{-1}(12 \%)$ less than noninoculated plots, despite little foliar symptom development (Fig. 1A). Average yield for the 17 June planting date was $730 \mathrm{~kg} \mathrm{ha}^{-1}(21 \%)$ less than the 24 May planting date. Although the cultivar $\times$ inoculation interaction was not significant in $2013(P=0.7190)$, all 10 cultivars showed significantly lower yields in the inoculated plots, with the yield differences between noninoculated and inoculated plots ranging from 410 to $790 \mathrm{~kg} \mathrm{ha}^{-1}$ (11 to 22\%) (Fig. 2A). Within the noninoculated plots, six other cultivars (AG1931, AG2531, CH2105R2, CH2305R2, P92Y32, and P92Y53) yielded similarly to the highest-yielding cultivar (P92Y51). For the inoculated

Table 3. Analysis of variance results for soybean sudden death syndrome (SDS) disease index (DX) and yield for 2013 to 2014

\begin{tabular}{llrrr}
\hline & & & \multicolumn{2}{c}{ Year $(\boldsymbol{P}>\boldsymbol{F})$} \\
\cline { 4 - 5 } Variable & Source of variation & Df $^{\mathbf{y}}$ & \multicolumn{1}{c}{$\mathbf{2 0 1 3}$} & $\mathbf{2 0 1 4}$ \\
\hline DX $^{z}$ & Planting date (PD) & 2 & $<0.0001$ & $<0.0001$ \\
& Cultivar (C) & 9 & $<0.0001$ & $<0.0001$ \\
& PD $\times$ C & 18 & 0.0267 & 0.0014 \\
Yield & Planting date (PD) & 2 & 0.0001 & 0.0008 \\
& Cultivar (C) & 9 & $<0.0001$ & 0.0002 \\
& PD $\times$ C & 18 & 0.3100 & 0.2641 \\
& Inoculation (I) & 1 & $<0.0001$ & 0.0001 \\
& PD $\times$ I & 2 & 0.0059 & $<0.0001$ \\
& C $\times$ I & 9 & 0.7190 & 0.0219 \\
& PD $\times$ C $\times$ I & 18 & 0.9605 & 0.9481 \\
\hline
\end{tabular}

${ }^{y} \mathrm{Df}=$ degree of freedom.

${ }^{z}$ The inoculation treatment was removed for the DX analysis due to $<1 \%$ of noninoculated sub-subplots (i.e., the experimental unit) expressing foliar SDS symptoms.

Table 2. Average monthly air temperature $\left({ }^{\circ} \mathrm{C}\right)$, accumulated precipitation $(\mathrm{mm})$, and irrigation total (mm) from 1 April to 30 September for the Hancock Agricultural Research Station from 2013 to 2014

\begin{tabular}{|c|c|c|c|c|c|c|c|}
\hline \multirow[b]{2}{*}{ Year } & \multirow[b]{2}{*}{ Weather variable } & \multicolumn{6}{|c|}{ Month $^{\mathrm{z}}$} \\
\hline & & April & May & June & July & August & September \\
\hline \multirow[t]{3}{*}{2013} & Temperature, ${ }^{\circ} \mathrm{C}$ & $3.9(-3.9)$ & $14.0(+0.1)$ & $18.2(-1.2)$ & $20.8(-1.4)$ & $20.2(-0.4)$ & $16.3(+0.2)$ \\
\hline & Precipitation, mm & $112(+36)$ & $138(+36)$ & $151(+37)$ & $46(-63)$ & $45(-52)$ & $50(-39)$ \\
\hline & Irrigation, mm & 0 & 0 & 13 & 140 & 160 & 76 \\
\hline \multirow[t]{3}{*}{2014} & Temperature, ${ }^{\circ} \mathrm{C}$ & $5(-2.8)$ & $13.9(-0.5)$ & $19.8(+0.4)$ & $18.8(-3.4)$ & $19.9(-0.7)$ & $14.6(-1.5)$ \\
\hline & Precipitation, $\mathrm{mm}$ & $167(+88)$ & $50(-52)$ & $130(+13)$ & $40(-67)$ & $196(+105)$ & $66(-20)$ \\
\hline & Irrigation, $\mathrm{mm}$ & 0 & 10 & 48 & 138 & 72 & 20 \\
\hline
\end{tabular}

${ }^{\mathrm{z}}$ Values in parentheses represent the deviation from the 30-year average. 
plots, the cultivar P92Y51 was again the highest-yielding, and cultivars CH2105R2 and CH2305R2 yields were statistically similar (Fig. 2A). The yield results from the inoculated plots demonstrated the two cultivars that consistently had the lowest $\mathrm{DX}$ values $(\mathrm{CH} 2105 \mathrm{R} 2$ and P92Y51) were also among the highest-yielding. In spite of displaying some of the highest levels of SDS symptoms, the cultivar CH2305R2 was also among the highest-yielding under inoculated conditions.

The average yield in 2014 was $1,000 \mathrm{~kg} \mathrm{ha}^{-1}$ (32\%) less than the average yield in 2013 (data not shown). In 2014, the planting date $\times$ inoculation and cultivar $\times$ inoculation interactions were significant (Table 3). For the planting date $\times$ inoculation interaction, the yield difference between noninoculated and inoculated plots in the 5 May planting date was $400 \mathrm{~kg} \mathrm{ha}^{-1}(12 \%)$ (Fig. 1B). Even though little SDS symptom development occurred in the 22 May planting date, inoculated plots yielded $270 \mathrm{~kg} \mathrm{ha}^{-1}(9 \%)$ less than noninoculated plots (Fig. 1B). Yield was again greater for the early May planting date, with the 5 May planting date averaging $340 \mathrm{~kg} \mathrm{ha}^{-1}(11 \%)$ more than the 22 May planting date. Furthermore, yield for the inoculated plots in the 5 May planting date was the same as the yield for the noninoculated plots in the 22 May planting date (Fig. 1B). Unlike 2013, no yield difference was observed between noninoculated and inoculated plots in the third planting date (11 June) (Fig. 1B). Average yield for the 11 June planting date was $490 \mathrm{~kg} \mathrm{ha}^{-1}(18 \%)$ less than the average yield for the 22 May planting date.

For the cultivar $\times$ inoculation interaction, five of the 10 cultivars (AG1921, AG2431, AG2531, CH2305R2, and P92Y32) showed significantly lower yields in the inoculated plots, with yield loss ranging from 260 to $410 \mathrm{~kg} \mathrm{ha}^{-1}$ (10 to 13\%) (Fig. 2B). Of these five cultivars, two (CH2305R2 and P92Y32) were among those that had the highest amounts of symptom development in 2014. The five remaining cultivars showed no difference between noninoculated and inoculated plots (Fig. 2B). The cultivars AG2431 and CH2305R2 yielded the highest within the noninoculated plots and were among the highest within the inoculated plots as well. For the inoculated plots, cultivars CH2105R2, P92Y12, and P92Y51 were also among the highest yielding. Similar to 2013, CH2105R2 and P92Y51 also displayed the lowest level of foliar symptom development.

\section{Discussion}

Results from this study support previous reports that foliar SDS symptom development is increased in early- versus late-planted soybean (Hershman et al. 1990; Wrather et al. 1995). When compared across both years, foliar symptom development was greatest in the

Table 4. Planting date $\times$ cultivar results for soybean sudden death syndrome (SDS) disease index (DX) $)^{\mathrm{y}}$ ratings in 2013 and 2014

\begin{tabular}{|c|c|c|c|c|c|c|}
\hline \multirow[b]{3}{*}{ Cultivar } & \multicolumn{6}{|c|}{ Planting date } \\
\hline & \multicolumn{3}{|c|}{2013} & \multicolumn{3}{|c|}{2014} \\
\hline & 6 May & 24 May & 17 June & 5 May & 22 May & 11 June \\
\hline AG1931 & $6.7 \mathrm{de}^{\mathrm{z}}$ & $7.2 \mathrm{bcA}$ & $0.0 \mathrm{aB}$ & $6.5 \mathrm{cA}^{\mathrm{z}}$ & $0.0 \mathrm{aB}$ & $0.7 \mathrm{aB}$ \\
\hline AG2431 & $11.9 \mathrm{cdA}$ & $11.2 \mathrm{abA}$ & $0.3 \mathrm{aB}$ & $7.0 \mathrm{cA}$ & $0.7 \mathrm{aB}$ & $0.0 \mathrm{aB}$ \\
\hline AG2531 & $17.1 \mathrm{abcA}$ & $12.9 \mathrm{abA}$ & $0.0 \mathrm{aB}$ & $10.8 \mathrm{bcA}$ & $0.3 \mathrm{aB}$ & $0.9 \mathrm{aB}$ \\
\hline $\mathrm{CH} 2105 \mathrm{R} 2$ & $7.0 \mathrm{de} A$ & $4.5 \mathrm{cA}$ & $0.0 \mathrm{aB}$ & $1.2 \mathrm{eA}$ & $0.4 \mathrm{aAB}$ & $0.0 \mathrm{aB}$ \\
\hline $\mathrm{CH} 2305 \mathrm{R} 2$ & $26.0 \mathrm{abA}$ & $19.5 \mathrm{aA}$ & $0.0 \mathrm{aB}$ & $31.8 \mathrm{aA}$ & $0.4 \mathrm{aB}$ & $0.4 \mathrm{aB}$ \\
\hline P92Y11 & $22.8 \mathrm{abcA}$ & $13.3 \mathrm{abA}$ & $0.3 \mathrm{aB}$ & $18.5 \mathrm{abA}$ & $0.9 \mathrm{aB}$ & $0.4 \mathrm{aB}$ \\
\hline P92Y12 & $12.6 \mathrm{bcdA}$ & $9.2 \mathrm{bcA}$ & $0.4 \mathrm{aB}$ & $5.2 \mathrm{cdA}$ & $0.0 \mathrm{aB}$ & $0.3 \mathrm{aB}$ \\
\hline P92Y32 & $27.8 \mathrm{aA}$ & $22.0 \mathrm{aA}$ & $0.0 \mathrm{aB}$ & $15.9 \mathrm{abA}$ & $0.9 \mathrm{aB}$ & $0.9 \mathrm{aB}$ \\
\hline P92Y51 & $4.0 \mathrm{eA}$ & $5.1 \mathrm{cA}$ & $0.0 \mathrm{aB}$ & $2.4 \mathrm{deA}$ & $0.0 \mathrm{aB}$ & $0.0 \mathrm{aB}$ \\
\hline P92Y53 & $6.7 \mathrm{deA}$ & $9.2 \mathrm{bcA}$ & $0.3 \mathrm{aB}$ & $5.7 \mathrm{cdA}$ & $0.0 \mathrm{aB}$ & $0.0 \mathrm{aB}$ \\
\hline
\end{tabular}

${ }^{y}$ DX was calculated using the formula 'disease incidence' $x$ 'disease severity' $\div 9$. Values only include those from the inoculated plots and were transformed for analysis using the equation $\log _{10}\left({ }^{\prime} \mathrm{DX} '+1\right)$. Back-transformed values are presented in this table.

${ }^{z}$ Means comparisons were calculated based on Fisher's protected least significant difference. The SLICE option in SAS (v. 9.3) was used to compare means of this interaction (Littell et al. 2006). Values followed by the same lowercase letter within a column (i.e., planting date) or by the same uppercase letter within a row (i.e., the cultivar) are not significantly different at $P \leq 0.05$. early May planting date. However, the planting date for which foliar symptom development significantly decreased was different each year. This occurred in the third planting (17 June) in 2013 and the second planting date (22 May) in 2014. During this study, aboveaverage precipitation occurred in May and June 2013 (Table 2), but rainfall events occurred before and after all three planting dates (data not shown). Although a precipitation deficit occurred in May 2014 , over $70 \%$ of the accumulated rainfall for May occurred within the first two weeks of the month. These soil moisture conditions, coupled with soil temperatures, at these different planting dates each year may explain this result. Unfortunately, soil temperature data were not available during this study. Using climatic and soil conditions to relate or predict SDS foliar symptom development have been challenging. Under field conditions, cool temperatures and high soil moisture early in the season are thought to favor disease development (Leandro et al. 2012). In growth chamber studies, root infection by $F$. virguliforme was greatest in cooler soil temperatures (15 to $17^{\circ} \mathrm{C}$ ), but expression of foliar symptoms was favored by higher temperatures $\left(25^{\circ} \mathrm{C}\right)$ (Scherm and Yang 1996). This is consistent with
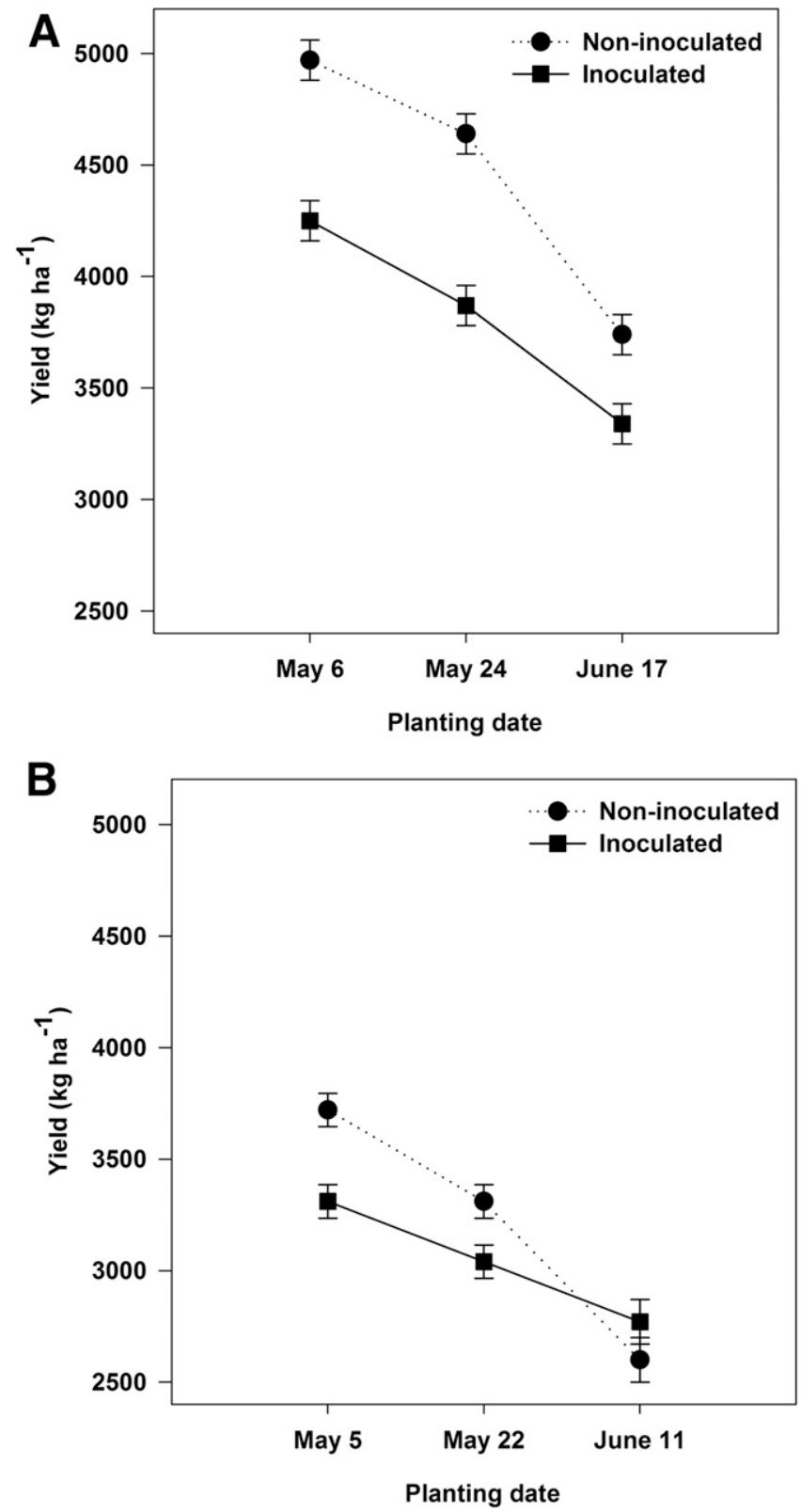

Fig. 1. Soybean yield for each planting date in plots inoculated with Fusarium virguliforme and not inoculated in Wisconsin in A, 2013 and B, 2014. Error bars are \pm 1 standard error of the mean. 
observations by McLean and Lawrence (1993) that cool temperatures at the beginning of the growing season followed by relatively high temperatures and adequate season-long moisture are optimal conditions for SDS symptom development. Research in Iowa comparing climate and soil conditions in SDS epidemic and nonepidemic years suggested that no single climatic factor determined disease development, but below-average soil temperature and above-average precipitation were associated with SDS outbreaks throughout the state (Leandro et al. 2013). The authors also suggested planting into cool soils might not be problematic if the remainder of the growing season is dry, and SDS outbreaks can be severe even when soil temperatures are above average at the time of plating.
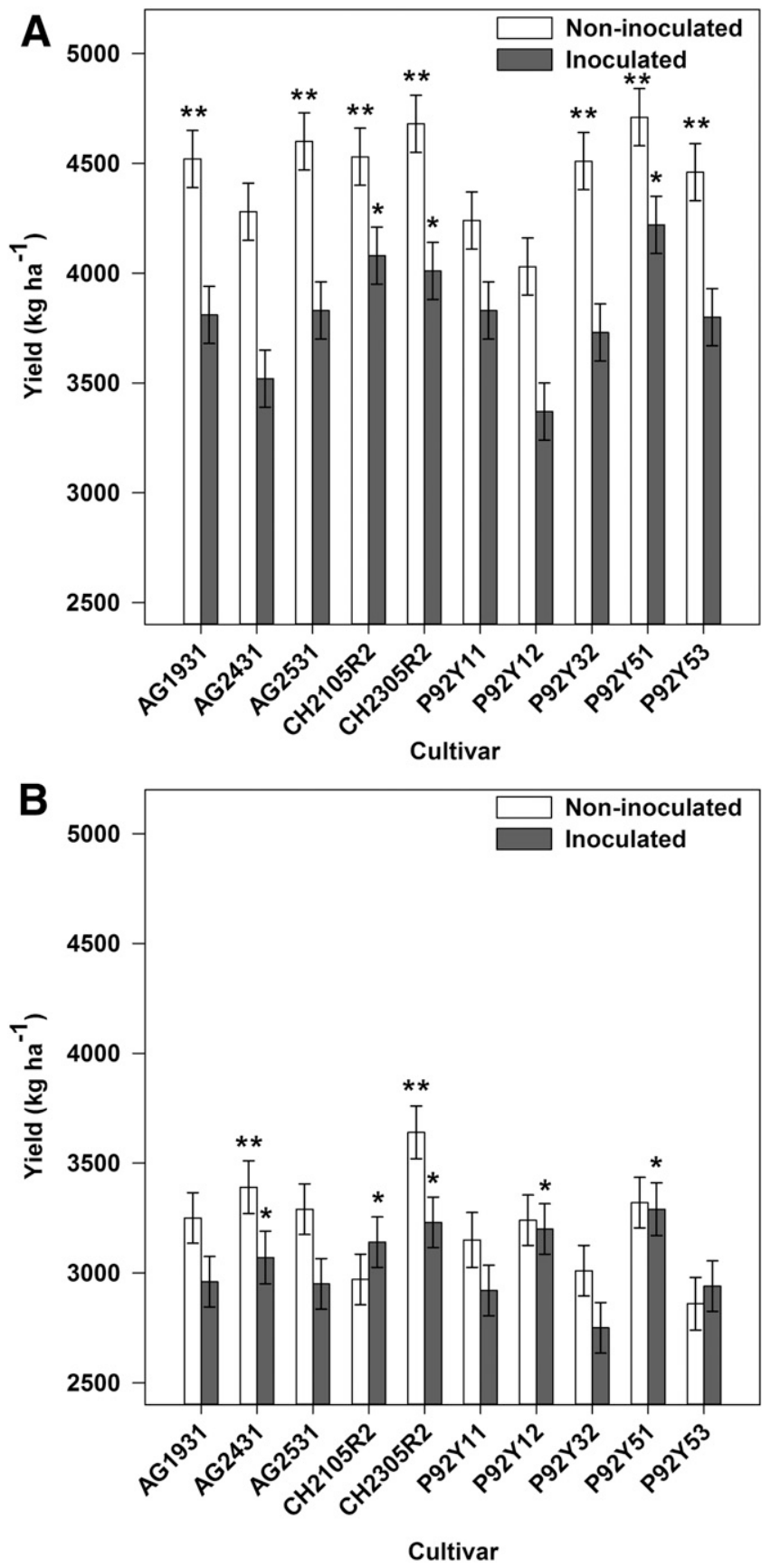

Fig. 2. Soybean yield for soybean cultivars inoculated with Fusarium virguliforme and not inoculated in Wisconsin in A, 2013 and B, 2014. Error bars are \pm 1 standard error of the mean. Means comparisons were calculated based on Fisher's protected least significant difference. The SLICE option in SAS (v. 9.3) was used to compare means within the interaction (Littell et al. 2006). Two asterisks $\left(^{*}\right)$ mean not statistically different from the highest-yielding cultivar within the noninoculated plots; one asterisk $\left(^{*}\right)$ means not statistically different from the highest-yielding cultivar within the inoculated plots.
Cultivar differences in SDS development observed in this study were not consistent in relation to their brand SDS rating (Table 1). Although the two cultivars used in this study that had the most resistant ratings by their respective companies (CH2105R2 and P92Y51) exhibited the least symptom development within high SDS environments (i.e., the first and second planting dates in 2013 and first planting date in 2014), the cultivars with the most susceptible disease ratings did not necessarily exhibit the greatest amount of symptom development. Based on the results from this study, only one cultivar (P92Y11) displaying the greatest amount of SDS development was consistent with its susceptible brand rating. The relationship between the brand rating and the rating given based on results from this study, as well as yield prediction based on brand rating, were inconsistent for the remaining cultivars. While $\mathrm{CH} 2105 \mathrm{R} 2$ and $\mathrm{P} 92 \mathrm{Y} 51$ were among the highest-yielding cultivars, especially when SDS symptoms were observed (i.e., the inoculated plots), the cultivar $\mathrm{CH} 2305 \mathrm{R} 2$ was also among the highest-yielding cultivars each year, in spite of being one of the cultivars expressing the greatest amount of symptom development each year. This cultivar may not have low resistance, as suggested by the seed company, but may have tolerance, because it was able to yield well despite having some of the greatest disease development. Studies have shown resistant SDS genotypes reduce SDS symptom development and lead to increased yield (Brzostowski et al. 2014; Swoboda et al. 2011). Correlation results from this study showed significant negative correlations between yield and SDS symptoms within all three planting dates in 2013 and within the first planting date in 2014. While significant, these results are likely due to the lower yields observed overall within the inoculated plots, coupled with the expression of SDS symptoms unlike their noninoculated counterparts. Further correlation analyses performed between yield and SDS symptoms within only the inoculated plots revealed a lack of correlation $(P>0.05)$ within all three planting dates each year (data not shown). Other reports have indicated disease development did not correlate well with yield (Hershman et al. 1990; Stephens et al. 1993). This lack of correlation may be due to timing of foliar symptom development as well as disease tolerance instead of resistance. Our results are consistent with Hershman et al. (1990), who reported first visible foliar symptoms did not occur until R5. At this growth stage, Hershman et al. (1990) suggested mild to moderate symptom development may have little effect on yield. While selecting cultivars with the best SDS resistance available is desired, results from this study indicate yield potential of a cultivar should be considered before SDS resistance.

This is the first study, to our knowledge, to examine the yield impact of SDS development within multiple planting dates. The studies by Hershman et al. (1990) and Wrather et al. (1995) performed field trials at sites with known histories of SDS and were not able to make comparisons within a planting date to determine potential yield loss compared with a control. In this study, the average yield difference between noninoculated and inoculated plots across both years was 560,530 , and $200 \mathrm{~kg} \mathrm{ha}^{-1}$ in the early May, late May, and midJune planting dates, respectively. A study in Iowa found soybean yield was $7 \%$ less in inoculated versus noninoculated plots across three site-years planted in the first week of May (Swoboda et al. 2011); however, the smaller yield difference is likely due to the lesser amount of SDS development in that study. Although SDS symptoms and yield loss were greatest in the early May planting date across both years, average yield was also greatest each year in the early May planting date. This is consistent with other studies in the upper Midwest, demonstrating yield is maximized with early May planting dates (De Bruin and Pedersen 2008, Gaspar and Conley 2015). Interestingly, during both years of this study, a yield difference between the noninoculated and inoculated plots was observed in the planting date in which SDS symptoms significantly decreased (i.e., 17 June in 2013 and 22 May in 2014), and this yield difference occurred despite little foliar symptom development. This indicated root infection by $F$. virguliforme likely occurred, but root observations were not made during this study to confirm this or to confirm root rot caused by other pathogens. The mechanisms and environmental conditions that dictate the incubation period are not yet known (Leandro et al. 2012), 
but it is speculated that changes in the soybean physiology during reproduction may be involved in determining this period (Rupe and Gbur 1995).

Results presented here suggest growers in Wisconsin should not sacrifice planting dates that maximize yield in order to reduce SDS development. Careful attention should be given to selecting cultivars with high yield potential as the first priority, and then, focus cultivar selection using company SDS ratings to maximize yield potential and profitability.

\section{Acknowledgments}

The authors wish to thank C. Groves, J. Gaska, and A. Roth for their technical assistance and support in conducting this research. The authors would also like to thank the Wisconsin Soybean Marketing Board for funding this research.

\section{Literature Cited}

Abdelsamad, N., Mbofung, G.C., Robertson, A.E., Liebman, M., and Leandro, L.F. 2012. Long-term crop rotations suppress soybean sudden death syndrom in Iowa. (Abstr.) Phytopathology 102 (Supplement 4):S4.1.

Aoki, T., O’Donnell, K., Homma, Y., and Lattanzi, A. 2003. Sudden-death syndrome of soybean is caused by two morphologically and phylogenetically distinct species within the Fusarium solani species complex-F. virguliforme in North America and F. tucumaniae in South America. Mycologia 95: 660-684.

Bernstein, E. R., Atallah, Z. K., Koval, N. C., Hudelson, B. D., and Grau, C. R. 2007. First report of sudden death syndrome of soybean in Wisconsin. Plant Dis. 91:1201.

Brar, H. K., Swaminathan, S., and Bhattacharyya, M. K. 2011. The Fusarium virguliforme toxin FvTox1 causes foliar sudden death syndrom-like symptoms in soybean. Mol. Plant Microbe Interact. 24:1179-1188.

Brzostowski, L. F., Schapaugh, W.T., Rzodkiewicz, P.A., Todd, T.C., and Little, C.R. 2014. Effect of host resistance to Fusarium virguiliforme and Heterodera glycines on sudden death syndrome disease severity and soybean yield. Plant Health Progress. Published online. doi:10.1094/PHP-RS-13-0100.

De Bruin, J. L., and Pedersen, P. 2008. Soybean seed yield response to planting date and seeding rate in the upper Midwest. Agron. J. 100:696-703.

Fehr, W. R., Caviness, C. E., Burmood, D. T., and Pennington, J. S. 1971. Stage of development descriptions for soybeans, Glycine $\max ($ L.). Merrill. Crop Sci. 11: 929-931.

Gaspar, A. P., and Conley, S. P. 2015. Responses of canopy reflectance, light interception, and soybean seed yield to replanting suboptimal stands. Crop Sci. 55:377-385

Hartman, G. L., Huang, Y. H., Nelson, R. L., and Noel, G. R. 1997. Germplasm evaluation of Glycine max for resistance to Fusarium solani, the causal organism of sudden death syndrome. Plant Dis. 81:515-518.

Hartman, G. L., Leandro, L. F. S., and Rupe, J. C. 2015. Sudden death syndrome. Pages 88-90 in: Compendium of Soybean Diseases and Pests. G. L. Hartman, J. C. Rupe, E. F. Sikora, L. L. Domier, J. A. David, and K. L. Steffey, eds. American Phytopathological Society, St. Paul, MN.

Heatherly, L. G., and Elmore, R. W. 2004. Managing inputs for peak production. Pages 451-536 in: Soybeans: Improvement, Production, and Uses. Boerma, H. R., and Specht, J. E., eds. American Society of Agronomy, Soil Science Society of America, Crop Science Society of America, Inc., Madison, WI.

Hershman, D. E., Hendrix, J. W., Stuckey, R. E., Bachi, P. R., and Henson, G. 1990. Influence of planting date and cultivar on soybean sudden death syndrome in Kentucky. Plant Dis. 74:761-766.

Hirrel, M. C. 1986. Disease severity and yield loss comparisons of soybean maturity groups affected in sudden death syndrome. (Abstr.) Proc. Southern Soybean Dis. Workers Conference. 15:61.

Hirrel, M. C. 1987. Sudden death syndrome of soybean: New insights into its development. Proc. Am. Seed Trade Assoc. Soybean Res. Conf. 16:95-104.

Hnetkovsky, N., Chang, S. J. C., Doubler, T. W., Gibson, P. T., and Lightfoot, D. A. 1996. Genetic mapping of loci underlying field resistance to soybean sudden death syndrome (SDS). Crop Sci. 36:393-400.

Koenning, S. R., and Wrather, J. A. 2010. Suppression of soybean yield potential in the continental United States by plant diseases from 2006 to 2009. Plant Health Progress. Online publication. doi:10.1094/PHP-2010-1122-01-RS
Leandro, L. F., Tatalovic, N., and Luckew, A. 2012. Soybean sudden death syndrome-Advances in knowledge and disease management. CAB Rev. 7: $1-14$.

Leandro, L.F.S., Robertson, A.E., Mueller, D.S., and Yang, X.B. 2013. Climatic and environmental trends observed during epidemic and non-epidemic years of soybean sudden death syndrome in Iowa. Plant Health Progress. Online publication. doi:10.1094/PHP-2013-0529-01-RS

Littell, R. C., Milliken, G. A., Stroup, W. W., Wolfinger, R. D., and Schabenberger, O. 2006. SAS for mixed models, 2nd Ed. SAS Publishing, Cary, NC.

Luo, Y., Hildebrand, K., Chong, S. K., Myers, O., and Russin, J. S. 2000. Soybean yield loss to sudden death syndrome in relation to symptom expression and root colonization by Fusarium solani f. sp. glycines. Plant Dis. 84:914-920.

Marburger, D., Conley, S., Esker, P., MacGuidwin, A., and Smith, D. 2014. Relationship between Fusarium virguliforme and Heterodera glycines in commercial soybean fields in Wisconsin. Plant Health Progress. Online publication. doi:10.1094/PHP-RS-13-0107

McLean, K. S., and Lawrence, G. W. 1993. Interrelationship of Heterodera glycines and Fusarium solani in sudden death syndrome of soybean. J. Nematol. 25:434-439.

Mueller, D. S., Hartman, G. L., Nelson, R. L., and Pedersen, W. L. 2002. Evaluation of Glycine max germ plasm for resistance to Fusarium solani f. sp. glycines. Plant Dis. 86:741-746.

Mueller, D. S., Nelson, R. L., Hartman, G. L., and Pedersen, W. L. 2003. Response of commercially developed cultivars and ancestral soybean lines to Fusarium solani f. sp. glycines. Plant Dis. 87:827-831.

Njiti, V. N., Shenaut, M. A., Suttner, R. J., Schmidt, M. E., and Gibson, P. T. 1998 Relationship between soybean sudden death syndrome disease measures and yield components in F6-derived lines. Crop Sci. 38:673-678.

Rowntree, S. C., Suhre, J. J., Weidenbenner, N. H., Wilson, E. W., Davis, V. M. Naeve, S. L., Casteel, S. N., Diers, B. W., Esker, P. D., Specht, J. E., and Conley, S. P. 2013. Genetic gain $\times$ management interactions in soybean: I. Planting date. Crop Sci. 53:1128-1138.

Roy, K. W., Rupe, J. C., Hershman, D. E., and Abney, T. S. 1997. Sudden death syndrome of soybean. Plant Dis. 81:1100-1111.

Rupe, J. C., and Gbur, E. E. 1995. Effect of plant age, maturity group, and the environment on the disease progress of sudden death syndrome of soybean. Plant Dis. 79:139-143.

Rupe, J. C., Gbur, E. E., and Marx, D. M. 1991. Cultivar responses to sudden death syndrome of soybean. Plant Dis. 75:47-50.

Rupe, J. C., Robbins, R. T., and Gbur, E. E. 1997. Effect of crop rotation on soil population densities of Fusarium solani and Heterodera glycines and on the development of sudden death syndrome of soybean. Crop Prot. 16:575-580.

Scherm, H., and Yang, X. B. 1996. Development of sudden death syndrome of soybean in relation to soil temperature and soil water matric potential. Phytopathology 86:642-649.

Stephens, P. A., Nickell, C. D., Moots, C. K., and Lim, S. M. 1993. Relationship between field and greenhouse reactions of soybean to Fusarium solani. Plant Dis. 77:163-166.

Swoboda, C. M., Pedersen, P., Esker, P. D., and Munkvold, G. P. 2011. Soybean yield response to plant distribution in Fusarium virguliforme infested soil. Agron. J. 103:1712-1716.

Vick, C. M., Bond, J. P., Chong, S. K., and Russin, J. S. 2006. Response of soybean sudden death syndrome to tillage and cultivar. Can. J. Plant Pathol. 28:77-83.

Vick, C. M., Chong, S. K., Bond, J. P., and Russin, J. S. 2003. Response of soybean sudden death syndrome to subsoil tillage. Plant Dis. 87:629-632.

Von Qualen, R. H., Abney, T. S., Huber, D. M., and Schreiber, M. M. 1989. Effects of rotation, tillage, and fumigation on premature dying of soybeans. Plant Dis. 77:163-166.

Wrather, J. A., Kendig, S. R., Anand, S. C., Niblack, T. L., and Smith, G. S. 1995. Effects of tillage, cultivar, and planting date on percentage of soybean leaves with symptoms of sudden death syndrome. Plant Dis. 79:560-562.

Wrather, J.A., and Koenning, S.R. 2009.Effects of diseases on soybean yields in the United States 1996 to 2007. Plant Health Progress. Online publication. doi:10.1094/PHP-2009-0401-01-RS

Xing, L., and Westphal, A. 2009. Effects of crop rotation of soybean with corn on severity of sudden death syndrome and population densities of Heterodera glycines in naturally infested soil. Field Crops Res. 112:107-117.

Yang, X. B., and Navi, S. S. 2010. Good harvest in corn should help manage soybean SDS. Integrated Pest Management News, Paper 375. Iowa State University. http://lib.dr.iastate.edu/cropnews/375. 